\title{
Influence of oxidation on fracture toughness of Carbon-Carbon Composites for high-temperature applications
}

\author{
B.V. Sunil Kumar \\ Department of Mechanical Engineering, Canara Engineering College, Mangalore, VTU, Karnataka, 574219, India. \\ sunilbv777@gmail.com, bttps:/ /orcid.org/0000-0002-3115-2141
}

V. Neelakantha Londe, M. Lokesha

Department of Mechanical Engineering, Mangalore Institute of Technology and Engineering, Moodabidri, VTU, Karnataka, 574225, India.

\author{
S.N. Vasantha Kumar \\ Department of Mechanical Engineering, Canara Engineering College, Mangalore, VTU, Karnataka, 574219, India.
}

\author{
A.O. Surendranathan \\ Department. of Metallurgical and Materials Engineering, NITK, Surathkal, Karnataka, 575025, India.
}

\begin{abstract}
Carbon-Carbon Composites (C-CC), used as composites for their remarkable qualities in the space industry and in many other industry sectors. C-CC has proven to be the most efficient material in extreme temperature situations. They are one among the best high-temperature materials with good thermal quality, such as high-temperature stability, outstanding thermal conductivity and low-temperature expansion coefficients. In aircraft, railways, trucks and even race vehicles, C-CC brake disks are in high demand. Compared to the favorable thermal and mechanical qualities of C-CC, their great sensitivity to oxidation in an oxidizing environment at temperatures even around $400^{\circ} \mathrm{C}$ is a major restriction with these composites. In particular, a study of the C-CC oxidation mechanism helps to create protective measures for these composites. The present experimental study explores the influence of oxidation in static air on the fracture toughness of C-CC. At a temperature of around $400^{\circ} \mathrm{C}$ to $700^{\circ} \mathrm{C}$ in an increment of $100^{\circ} \mathrm{C}$, an oxidation evaluation of the material is carried out. Results show that there was a significant decrease in the fracture toughness when there was an increase in temperature from $400^{\circ} \mathrm{C}$ to $700^{\circ} \mathrm{C}$. We can observe that C-CC fracture toughness is severely affected by oxidation. The decrease in the fracture toughness value in comparison with room temperature was $6 \%$ for $400^{\circ} \mathrm{C}$ and $45 \%$ for $700^{\circ} \mathrm{C}$.
\end{abstract}

KEYwords. Carbon-Carbon Composites; Fracture Toughness; Oxidation; SENB Specimen; ASTM D5045.

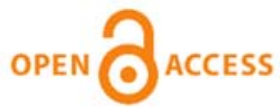

Citation: Kumar B. V., S., Londe, V. N., Lokesha, M., Vasantha Kumar, S.N., Surendranathan, A.O., Influence of oxidation on fracture toughness of Carbon-Carbon Composites for high-temperature applications, Frattura ed Integrità Strutturale, xx (2021) 105-113.

Received: 27.06 .2021

Accepted: 17.07.2021

Published: 01.10.2021

Copyright: (C) 2021 This is an open access article under the terms of the CC-BY 4.0, which permits unrestricted use, distribution, and reproduction in any medium, provided the original author and source are credited. 


\section{INTRODUCTION}

$\mathrm{B}$ ecause of its excellent long-durability, we employ composites for several applications, including architecture, cars, electronics, and biomedical engineering. Composites are employed in our daily lives. In recent decades, improved composite materials are used in the field of study, and novel fiber composites are being developed constantly. In the space sector and many other industries, Carbon-Carbon Composites (C-CC) are used as composites because of their unique characteristics. C-CC has been showed to be the most efficient material in extreme temperature conditions [1,2]. This special material was created at the end of the 1950s and designed for space travel only for the use of spatial programs until the late 1960s when space shuttles required materials such as lightweight, high thermal shock resistance, low heat expansion coefficients, high resistance to impact, high hardness, etc. [1-3].

The C-CC is one of the best high-temperature materials, with strong thermal properties such a high thermo stability (melting point $>3000^{\circ} \mathrm{C}$ ), excellent thermal conductivity and low-temperature expansion coefficients. Mechanical efficiency can be maintained even at severe temperatures. The good frictional properties with less wear are maintained throughout the temperature range [4-6]. These properties make it suitable for applications in high-speed airplanes such as the Airbus, Concord and Mirage. C-CC is a popular material for nose entrance tips, state-of-the-art wing material, rocket systems, highperformance turbojet engines, intercontinental ballistic rocket nose cones, vehicle braking systems, and other applications. Thanks to its unique quality and very low density. In Fig. 1. some of the applications are shown [7-10].

a

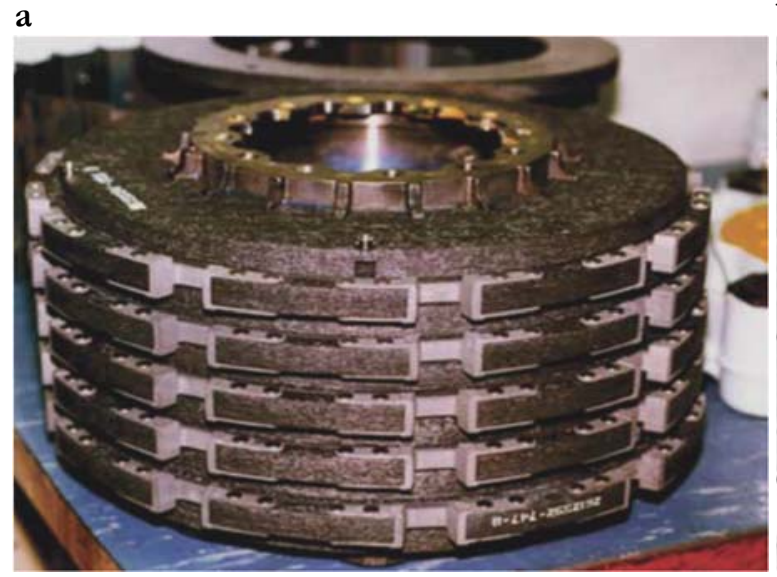

c

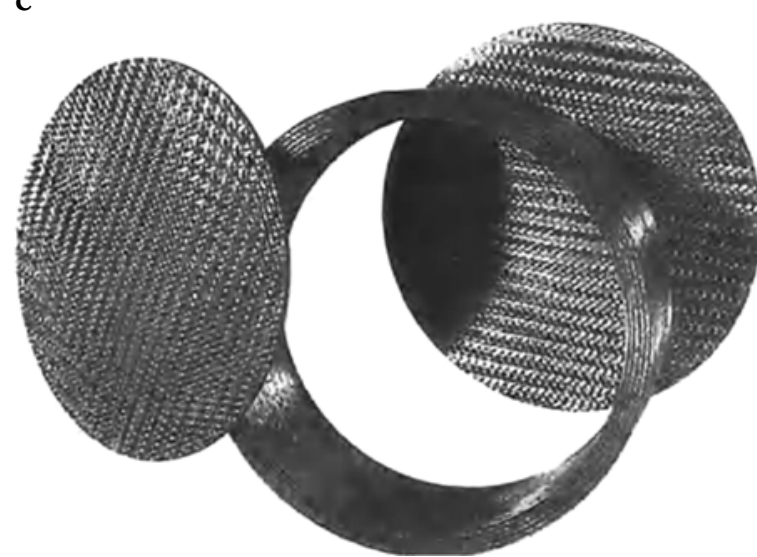

b



d

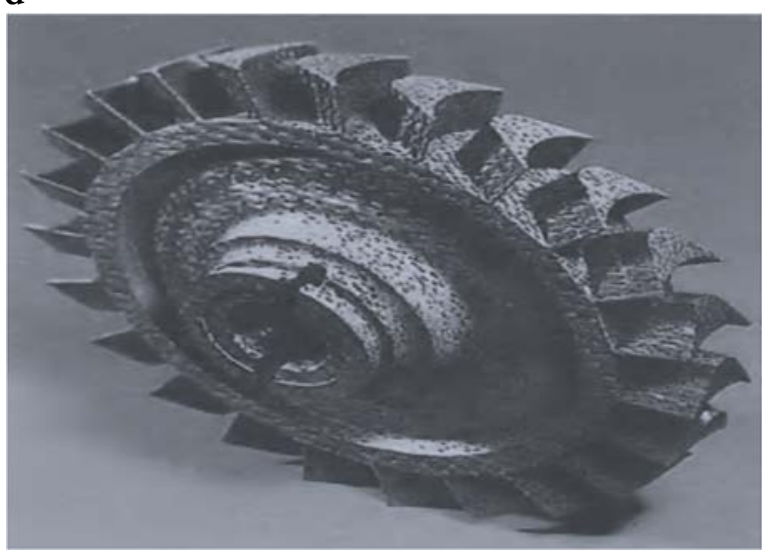

Figure 1: (a) C-CC Brake Disc [10] (b) Nose Cone for Missile [16] (c) Plates and Liners [1] (d) Turbine Rotor [1].

In aircraft, railways, vehicles, even racing automobiles, carbon brake disks are in high demand. For brake disks, around $60 \%$ of the applications are C-CC. C-CC are used in other fields and in aeronautical applications in recent years [7-10]. C-CC extends to challenging applications such as earthquakes and lightweight concrete systems in the building sector and infrastructure. They also have significant potential in the oil business, especially in crushing lines, drilling and deep oceans 
[1-3]. Compared to the favorable thermal and mechanical qualities of C-CC, their great sensitivity to oxidation in an oxidizing environment at temperatures even around $400^{\circ} \mathrm{C}$ is a major restriction with these composites. In particular, a study of the C-CC oxidation mechanism helps to create protective measures for these composites.

The mechanical properties of the C-CC recessed because of oxidation which were found in certain investigations. The effect of oxidation on mechanical proprieties is shown to be catastrophic. In the meantime decrease in flexural strength was attributed primarily to a decrease in fracture toughness rather than an increase in flaw size. The more the mass loss, the lower the failure stress. A significant number of studies have been carried out in order to understand the oxidation mechanisms for the oxidation behavior of C-CC. It was shown furthermore that the overall surface area other than porosity or gradual density and porous entry were controlled for the oxidation of C-CC. The oxidation took place at the contact between the fiber and matrix and subsequently advanced through the micro-cracks between the interfaces [11,12].

Fracture mechanics is considered the field of research related to engineering fractures and failures. The development of technical structures, materials, and installations, to ensure their technical safety, durability, and dependability, is based on fractures and damage prevention and evaluation [13,14]. Fracture toughness is a quantitative means of quantifying fracture resistance when there is a crack. This is an important feature of all materials, sometimes referred to as crack resistance, and used in all design applications in the fracture mechanic domain. The fact that fracture mechanics apply to common isotropic materials was also successfully established. Intralaminar fracture toughness is one of the problems with polymer composites (fiber-intensive cracking or matrix cracking). ASTM D 5045 [15] (plastic/particular polymer composites) testing methodologies for strain fracturing toughness are applied by investigators. These testing techniques based on ASTM D 5045 include loading pre-cracked specimen in tension or the three-point bending, which is shown in Fig. 2. [15,16]. Tension specimen is related as compact tension (CT) and three-point bending as single edge notch bend (SENB). In comparison to other specimen configurations, CT and SENB geometries are recommended since they feature mostly bending stress levels that allow smaller sample sizes for plane stress. The specimen thickness is denoted as ' $\mathrm{B}$ ' and ' $\mathrm{W}$ ' is specimen width ' $\mathrm{W}=2 \mathrm{~B}$ '. The crack length ' $a$ ' is selected such that $0.45<\mathrm{a} / \mathrm{W}<0.55$ for both these configuration [16,17].

a

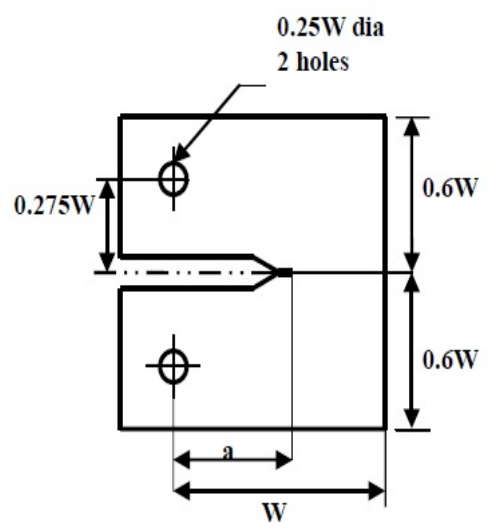

b

Figure 2: (a) CT Specimen (b) SENB Specimen [15,16]



B

At $400^{\circ} \mathrm{C}$ and above, C-CC interacts with oxygen. These materials have long-term usage at high temperatures, so they must therefore be evaluated for the fracture toughness in this respect. The oxidation test of the samples in static air at temperature of around $400^{\circ} \mathrm{C}$ to $700^{\circ} \mathrm{C}$ was carried out in the current investigation. The temperature was raised in an increment of $100^{\circ} \mathrm{C}$. The heating of specimens was carried out in a tubular furnace for about 10 to 15 minutes until the required temperature was attained and a thermocouple monitored and controlled the temperature. SENB specimen configuration having a thickness (B) of $10 \mathrm{~mm}$ is used in Mode I loading conditions. (a/W) ratio taken for the study is 0.45 .

\section{MATERIALS AND EXPERIMENTAL METHODS}

\section{Fabrication and Specimen Preparation of Carbon-Carbon Composite}

7 he liquid phase impregnation technology is utilized to manufacture the composites. The material having a '2D' fiber architecture is used in the fabrication process. This process impregnates liquid impregnates such charcoal tar, oil pitches, and thermosetting resins which provide high carbon content. Initially, a compression mold procedure 
formed the carbon and phenolic laminates from carbon materials in the form of a disk. The combined phenolic and 2D carbon fibers in a pitch are impregnated over $300^{\circ} \mathrm{C}$. Laminates are carbonized at $1000^{\circ} \mathrm{C}$ in an inert environment (very pure nitrogen) and then pitched in petrol (Densification). The densification process contains 3 phases, pitch impregnation, up to $700^{\circ} \mathrm{C}$ high-pressure carbonizations at a pressure of about 1000 bar, and above $2000^{\circ} \mathrm{C}$ graphitization. The densification cycles are repeated to achieve the required $1.8 \mathrm{~g} / \mathrm{cc}$ density. The test specimen employed is SENB as discussed and created by produced laminates per ASTM D 5045 standards $[15,16]$.

\section{Fracture Toughness Testing}

Laminates fabricated are machined to make SENB specimens. The first portion of the ' $\mathrm{V}$ ' notch is made with a cutter and a starting crack known as 'pre-crack' is placed at the root of the notch with a fine jewel saw. The $(\mathrm{a} / \mathrm{W})$ ratio taken for the study is 0.45 . Five samples have been examined for each condition. The testing is conducted by United Calibration Corporation made universal testing equipment with a crosshead speed of $1 \mathrm{~mm} / \mathrm{min}$, under standard ASTM D5045.

Tests were carried out at room temperature $\left(28^{\circ} \mathrm{C}\right)$ initially and later to find an effect of oxidation, samples were heated in a tubular furnace in static air at a temperature of around $400^{\circ} \mathrm{C}$ to $700^{\circ} \mathrm{C}$ in an increment of $100^{\circ} \mathrm{C}$. The heating of specimens was carried out for about 10 to 15 minutes until the required temperature was attained and a thermocouple monitored and controlled the temperature. Later the samples were removed from the furnace and cooled to room temperature to carry out the fracture toughness testing. Load against displacement curves are entered and the load PQ is computed as illustrated in Fig. 3a for calculating fracture toughness. Using Eqn.1 [15,16] fracture toughness (KIC) is calculated based on geometrical parameters of samples as shown in Fig. 3b.

$$
\begin{aligned}
& K_{I C}=\left(\frac{P_{Q}}{B W^{1 / 2}}\right) f(x) \\
& f(x)=6 x^{1 / 2} \frac{\left(1.99-x(1-x)\left(2015-3.93 x+2.7 x^{2}\right)\right)}{(1+2 x)\left(1-x^{3 / 2}\right)}
\end{aligned}
$$

where, $x=(a / W)$


Figure 3: (a) Determination of $\mathrm{P}_{\mathrm{Q}}$ [15] (b) Geometrical Parameters for SENB Specimen Testing

\section{RESULTS AND DISCUSSION}

\section{Fracture Toughness}

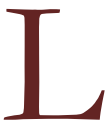

oad to displacement curve is obtained for room temperature and oxidation temperatures discussed as shown in Fig. 4 and calculated corresponding fracture toughness is tabulated in Tab. 1 and shown in Fig. 5. 




Figure 4: Load to Displacement Curve for Various Temperatures

\begin{tabular}{rccccc}
\hline $\begin{array}{c}\text { Sl } \\
\text { No. }\end{array}$ & Temperature $\left({ }^{\circ} \mathrm{C}\right)$ & $\begin{array}{c}\mathrm{P}_{\max } \\
(\mathrm{kN})\end{array}$ & $\begin{array}{c}\mathrm{P}_{\mathrm{Q}} \\
(\mathrm{kN})\end{array}$ & $\begin{array}{c}\text { Fracture Toughness } \\
\mathrm{K}_{\mathrm{IC}}(\operatorname{MPa} \sqrt{m})\end{array}$ & $\begin{array}{c}\text { Variation in } \mathrm{K}_{\text {IC to }} \\
\text { Room Temp. }\end{array}$ \\
\hline 1 & $28^{\circ} \mathrm{C}$ (Room Temperature) & 1.35 & 1.28 & 8.27 & - \\
2 & $400^{\circ} \mathrm{C}$ & 1.27 & 1.20 & 7.75 & $6 \%$ \\
3 & $500^{\circ} \mathrm{C}$ & 1.17 & 1.05 & 6.78 & $18 \%$ \\
4 & $600^{\circ} \mathrm{C}$ & 1.06 & 0.90 & 5.81 & $29 \%$ \\
5 & $700^{\circ} \mathrm{C}$ & 0.81 & 0.70 & 4.52 & $45 \%$ \\
\hline
\end{tabular}

Table 1: Fracture Toughness Results at Various Temperatures

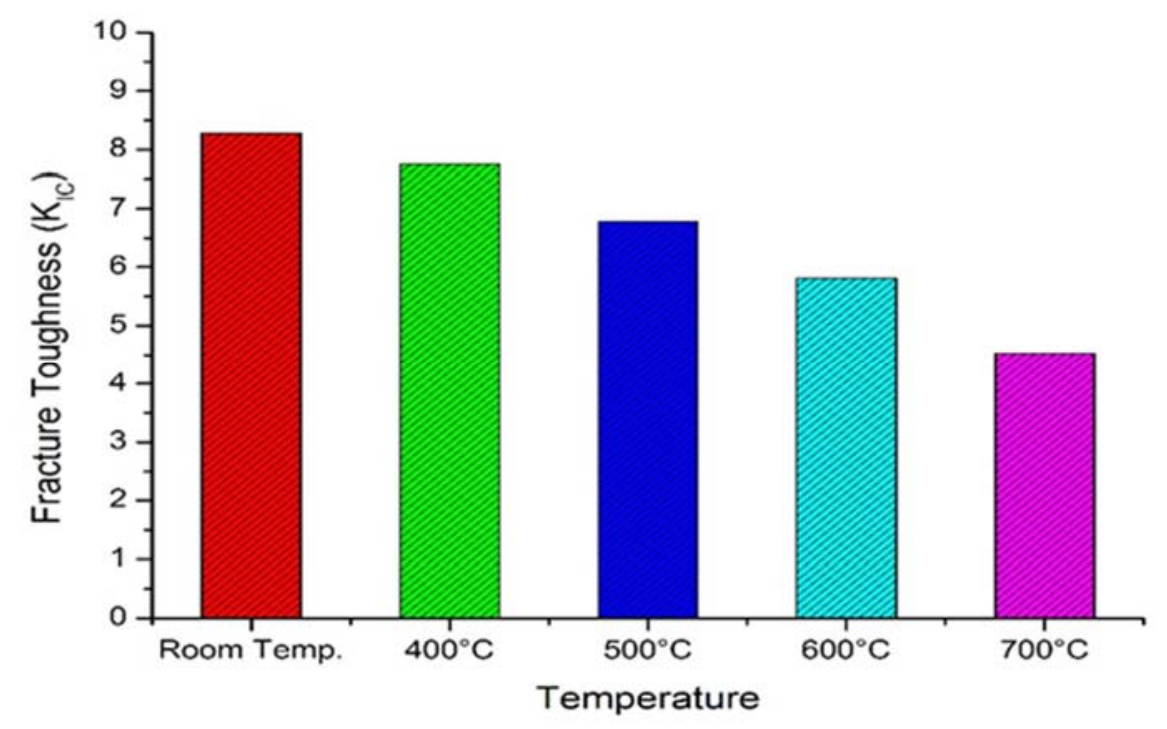

Figure 5: Fracture Toughness at Various Temperatures 
From the results, we observed that there was a significant decrease in the fracture toughness when there was an increase in temperature from $400^{\circ} \mathrm{C}$ to $700^{\circ} \mathrm{C}$. We can observe that $\mathrm{C}$-CC fracture toughness is severely affected by oxidation. The decrease in the fracture toughness value in comparison with room temperature was $6 \%$ for $400^{\circ} \mathrm{C}$ and $45 \%$ for $700^{\circ} \mathrm{C}$. The fracture toughness was drastically reduced. Weight loss is readily demonstrated by oxidation in C-CC. Oxidation protection, therefore, has to be done by various techniques for $\mathrm{C}-\mathrm{CC}$ in this respect.

Scanning Electron Microscope (SEM) Analysis

SEM micrographs were obtained using the scanning electron microscope (Model: S 3500, Make: Hitachi). The fractured CCC surface at room temperature depicted in Fig. 6 shows the brittle behavior of fractures. In certain regions, porosity is seen. The fracture results from the extraction of fiber and the decomposition of fiber are processes that consume energy.

a

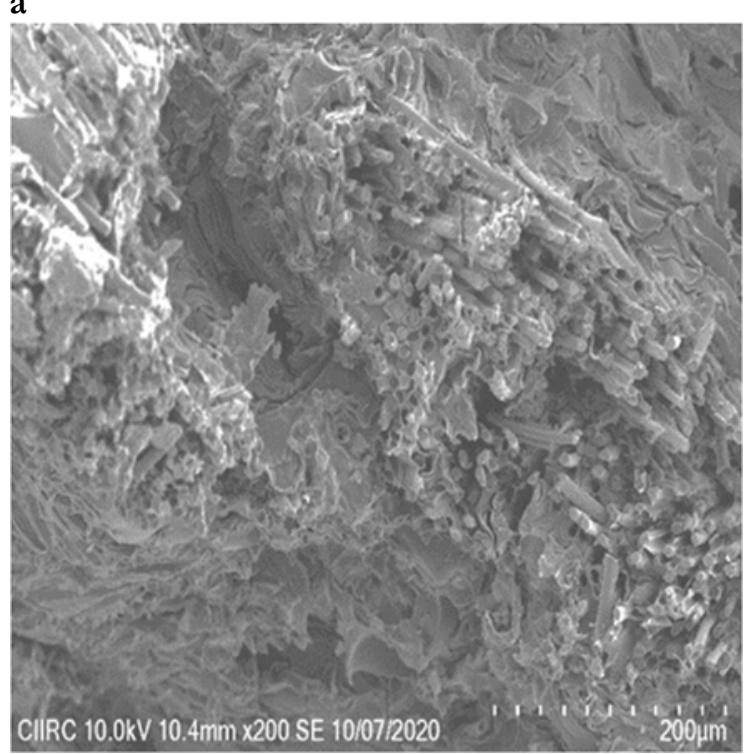

c

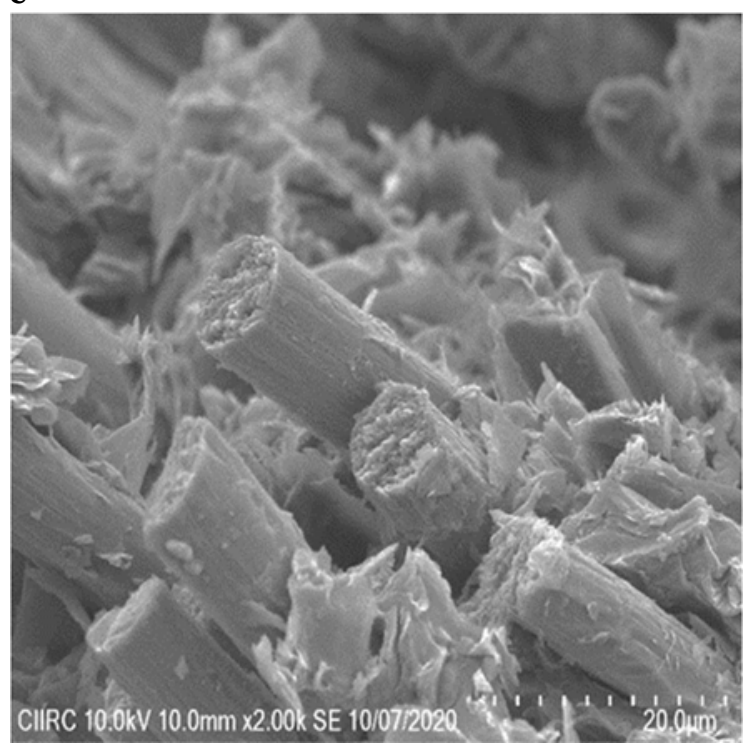

b

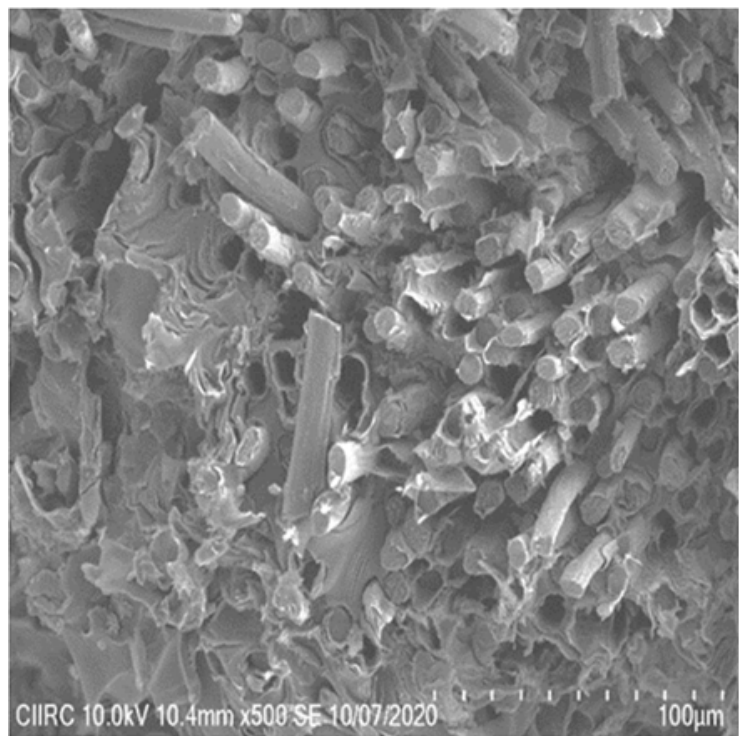

d



Figure 6: Fractured SEM Images of C-CC at Room Temperature for different magnifications (a) x 200 (b) x 500 (c) x $2 \mathrm{~K}$ (d) $\mathrm{x} 2 \mathrm{~K}$. 
a

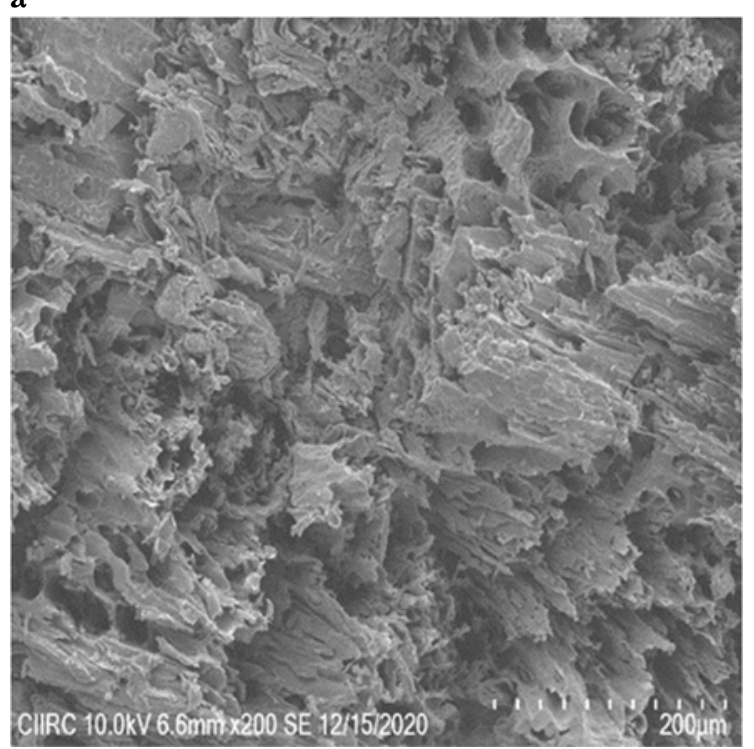

b

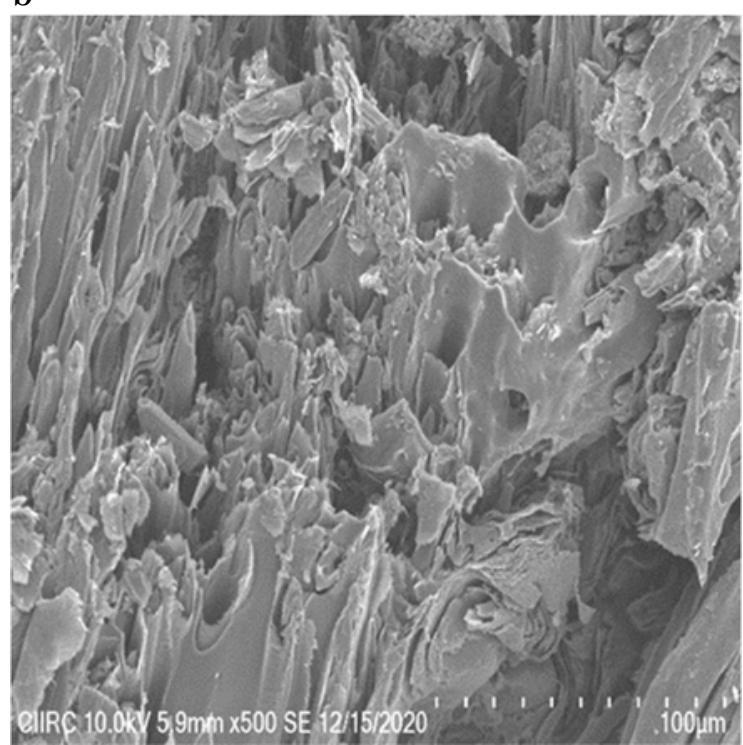

d

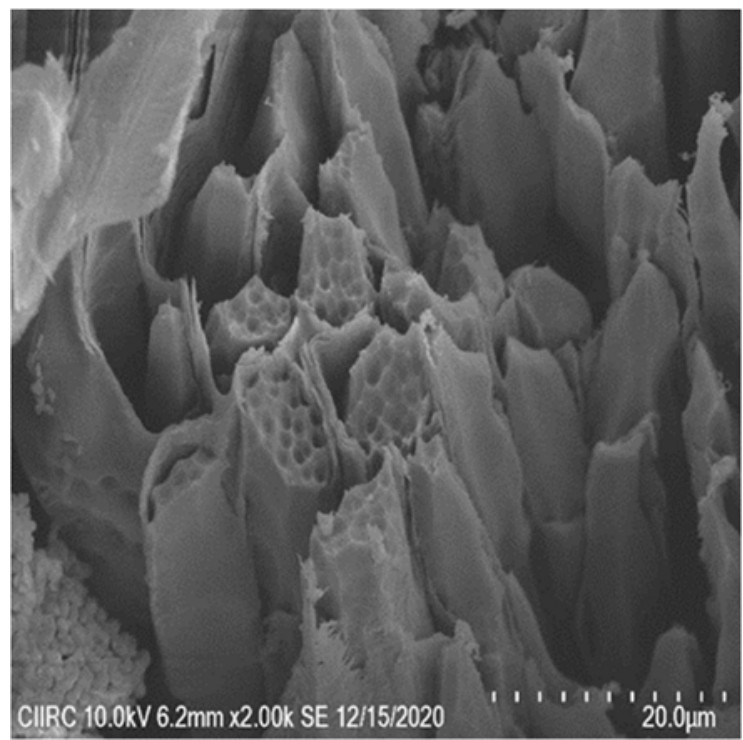

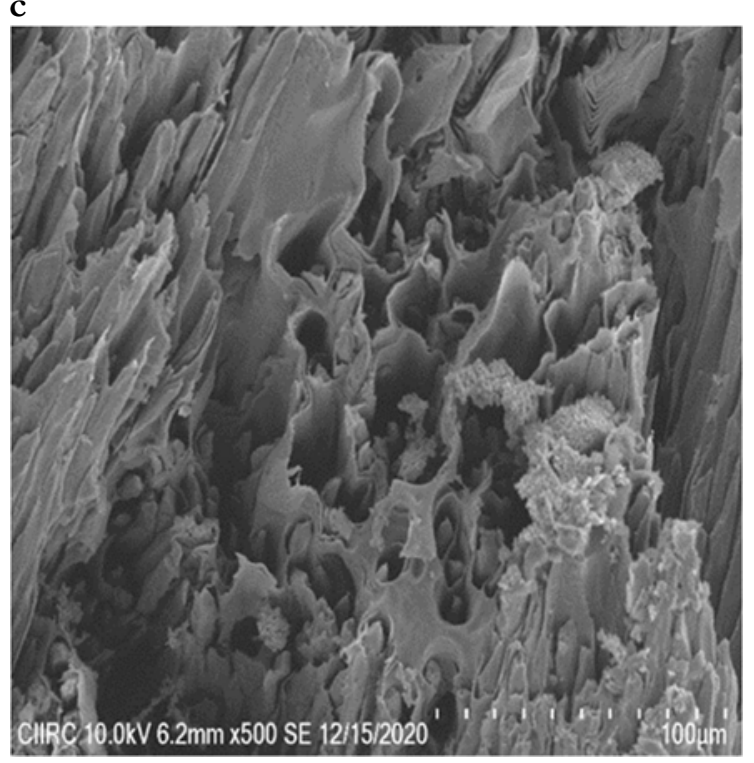

Figure 7: Fractured SEM Images of C-CC after oxidation Fractured SEM Images of C-CC after oxidation for different magnifications (a) $\times 200$ (b) $\times 500$ (c) $\times 500$ (d) $\times 2 \mathrm{~K}$.

We can observe from Fig. 7 that the C-CC burning away very rapidly due to oxidation. The burning started above $500^{\circ} \mathrm{C}$ and the creation of holes and cracks in the matrix has gradually taken place. We may witness the formation of huge pores between the fiber bundles. Fiber and matrix were oxidized at the same time, however, the matrix was first burnt resulting in quick damage to the oxygen penetration in the fibers. The fiber diameter is also dramatically reduced and ends are sharply reduced when compared to the starting diameter following oxidation. The coefficient of thermal expansion between fiber and matrix shows a difference and this causes potential stress on the interface. The tensile stress may lead to little fractures known as debonding. The cracks allow oxygen to enter and oxidization to accelerate. As a result, when oxidation took place, the circumferential gap depth was increased. The breadth of the gaps is increased by increasing the oxidation temperature. Furthermore, the spaces are gradually linked. 


\section{CONCLUSIONS}

he following conclusions are formed from the results, discussion, and analysis.

The heat treatment procedure plays an extremely important part in the manufacture of C-CC. It is necessary to densify through pitch impregnation. If the composites are not appropriately densified, composites with less density will not be suitable for several applications.

$>$ From the results, we observed that there was a significant decrease in the fracture toughness when there was an increase in temperature from $400^{\circ} \mathrm{C}$ to $700^{\circ} \mathrm{C}$. We can observe that $\mathrm{C}-\mathrm{CC}$ fracture toughness is severely affected by oxidation. The decrease in the fracture toughness value in comparison with room temperature was $6 \%$ for $400{ }^{\circ} \mathrm{C}$ and $45 \%$ for $700^{\circ} \mathrm{C}$. The fractured C-CC surface at room temperature shows the brittle behavior of fractures. In certain regions, porosity is seen. The fracture results from the extraction of fiber and the decomposition of fiber are processes that consume energy.

$>$ The creation of holes and cracks in the matrix has gradually taken place. We may witness the formation of huge pores between the fiber bundles. Fiber and matrix were oxidized at the same time, however, the matrix was first burnt resulting in quick damage to the oxygen penetration in the fibers.

$>$ The fracture toughness has drastically reduced and weight loss is readily demonstrated by oxidation in C-CC Oxidation protection, therefore, has to be done by various techniques for C-CC in this respect.

\section{ACKNOWLEDGMENTS}

he author Sunil Kumar B.V. would like to thank Advanced Systems Laboratory, Hyderabad for providing research facilities and study support.

\section{REFERENCES}

[1] Fitzer, E., Manocha, L.M. (2001).Carbon reinforcements and carbon/carbon composites. Annales de Chimie Science des Materiaux, 26, pp. 93-4.

[2] Savage, G. (1993).Applications of Carbon-carbon composites. Carbon-Carbon Composites, Springer, pp. 323-59.

[3] Devi, G.R., Rao, K.R. (1993). Carbon Carbon Composites: An Overview., Def. Sci. J., 43(4), pp. 369.

[4] Windhorst, T., Blount, G. (1997). Carbon-carbon composites: a summary of recent developments and applications, Mater. Des., 18(1), pp. 11-5.

[5] Das, T.K., Ghosh, P., Das, N.C. (2019). Preparation, development, outcomes, and application versatility of carbon fiber-based polymer composites: a review, Adv. Compos. Hybrid Mater., pp. 1-20.

[6] Arabab, S. (2015). Research in carbon-carbon composites, Open SIUC.

[7] Manocha, L.M. (2003). High performance carbon-carbon composites, Sadhana, 28(1-2), pp. 349-58.

[8] Scarponi, C. (2016).Carbon--carbon composites in aerospace engineering. Advanced Composite Materials for Aerospace Engineering, Elsevier, pp. 385-412.

[9] Lim, D.-W., Kim, T.-H., Choi, J.-H., Kweon, J.-H., Park, H.-S. (2008). A study of the strength of carbon--carbon brake disks for automotive applications, Compos. Struct., 86(1-3), pp. 101-6.

[10] Gadow, R., Jiménez, M. (2019). Carbon fiber-reinforced carbon composites for aircraft brakes, Am. Ceram. Soc. Bull., 98(6), pp. 28-34.

[11] McKee, D.W. (1987). Oxidation behavior and protection of carbon/carbon composites, Carbon N. Y., 25(4), pp. 5517.

[12] Zhang, C., Yan, K., Qiao, S., Li, M., Han, D., Guo, Y. (2012). Effect of oxidation on fracture toughness of a carbon/carbon composite, J. Wuhan Univ. Technol. Sci. Ed., 27(5), pp. 944-7.

[13] Kuna, M. (2013). Finite elements in fracture mechanics, 10, Springer.

[14] Gdoutos, E.E. (2020). Fracture mechanics: an introduction, vol. 263, Springer Nature.

[15] D5045--14. (2014). Standard Test Methods for Plane-Strain Fracture Toughness and Strain Energy Release Rate of Plastic Materials 1, ASTM J, 99, pp. 1-9.

[16] Kumar, B.V.S., Londe, V.N., Lokesha, M., Anilas, M., Surendranathan, A.O. (2021). Experimental investigation on 
Mode-I fracture toughness of Carbon-Carbon composites fabricated by preformed yarn method, Mater. Today Proc.. [17] Zhu, X.-K., Joyce, J.A. (2012). Review of fracture toughness (G, K, J, CTOD, CTOA) testing and standardization, Eng. Fract. Mech., 85, pp. 1-46. 